\title{
Study of Microstructure and Thermal Properties of the Low Melting Bi-In-Sn Eutectic Alloys
}

\author{
Ivana Manasijevića *®i, Ljubiša Balanovića, Tamara Holjevac Grgurićb ${ }^{b}$ Duško Minićc, \\ Milan Gorgievski ${ }^{a}$ \\ ${ }^{a}$ Technical Faculty in Bor, University of Belgrade, Bor, Serbia \\ ${ }^{b}$ Faculty of Metallurgy, University of Zagreb, Sisak, Croatia \\ ${ }^{c}$ Faculty of Technical Sciences, University of Pristina, Kosovska Mitrovica, Serbia
}

Received: July 16, 2018; Revised: September 05, 2018; Accepted: September 06, 2018

\begin{abstract}
Beside their technological importance in soldering, the low melting eutectic alloys based on bismuth and indium have potential for commercial application in the field of phase-change materials (PCMs). In this respect, the knowledge of their microstructure and thermal properties such as melting temperature, latent heat of melting, supercooling tendency, thermal conductivity, etc. is of large importance. In this study, two ternary eutectic Bi-In-Sn alloys were investigated by means of scanning electron microscopy (SEM) with energy dispersive X-ray spectrometry (EDS) and differential scanning calorimetry (DSC). Microstructure of the prepared eutectic alloys was analyzed using SEM-EDS and identification of co-existing phases was done. Melting temperatures and latent heats of eutectic melting were measured using DSC technique. Experimentally obtained results were compared with the results of thermodynamic calculation according to CALPHAD (calculation of phase diagram) approach and good mutual agreement was obtained.
\end{abstract}

Keywords: Bi-In-Sn system, eutectic alloy, latent heat of melting, DSC.

\section{Introduction}

Phase change materials (PCMs) are materials with high heat of fusion which undergo melting/solidification process at a constant or nearly constant temperature and absorb/ release thermal energy from/to the surroundings ${ }^{1}$. PCMs are extensively used in the field of thermal management and thermal energy storage ${ }^{1-3}$, such as electronics cooling ${ }^{1,4-6}$, energy storage for buildings ${ }^{7}$, solar energy systems ${ }^{8}$ and space systems ${ }^{9}$.

Low melting metals and eutectic alloys represent relatively new class of PCMs ${ }^{1,6,10,11}$. The main advantages of low melting metallic materials usage as PCMs are their high thermal conductivity and high volumetric latent heat ${ }^{6,10}$.

Low melting eutectic alloys based on bismuth and indium are among the best candidates for middle temperature PCMs (with operating temperature from 40 to $\left.200^{\circ} \mathrm{C}\right)^{6}$. However, many important thermo-physical properties such as melting point, latent heat of fusion, specific heat capacity, thermal conductivity for many low melting bismuth and indium based eutectics are still unknown ${ }^{10}$.

The aim of this work is experimental and analytical investigation of microstructure, melting temperatures and latent heats of fusion for the eutectic alloys from the Bi-InSn ternary system.

Prepared eutectic alloys were investigated using SEMEDS and DSC techniques. Experimentally obtained results

*e-mail: ivanamanasijevic80@gmail.com were compared with the results of phase equilibria calculation according to the CALPHAD method.

\section{Literature Review}

The phase diagrams of the Bi-Sn, Bi-In, and In-Sn constitutive binary systems are relatively well determined both experimentally and by theoretical calculations ${ }^{12}$.

Phase diagram of the $\mathrm{Bi}-\mathrm{Sn}$ system is presented in Figure 1. It is calculated using the optimized thermodynamic parameters from the latest thermodynamic assessment by Vizdal et al. ${ }^{13}$, carried out in the scope of the COST 531 Action $^{14}$ and included in the COST 531 database ${ }^{15}$. The BiSn system represents a simple eutectic system with eutectic reaction at $138.4^{\circ} \mathrm{C}$. It includes two equilibrium phases at room temperature, $(\mathrm{Bi})$ solid solution (rhombohedral A7-type structure) and ( $\beta \mathrm{Sn})$ solid solution (bct structure).

Phase diagram of the In-Sn binary system, given in Figure 2, is based on thermodynamic assessment by Ansara et al. ${ }^{16}$ included in the COST 531 database $^{15}$. Calculated phase diagram is in very good agreement with the experimentally established phase diagram by Moelans et al. ${ }^{17}$. The In-Sn system is composed of four solid phases: (In) (tetragonal) and ( $\mathrm{Sn}$ ) solid solutions and In-rich $\beta$ and Sn-rich $\gamma$ intermediate phases.

Microstructure, mechanical and thermophysical properties of the eutectic Bi-Sn and In-Sn alloys have been extensively studied mainly due to their large importance in lead-free soldering ${ }^{18-20}$. They possess low melting temperatures 


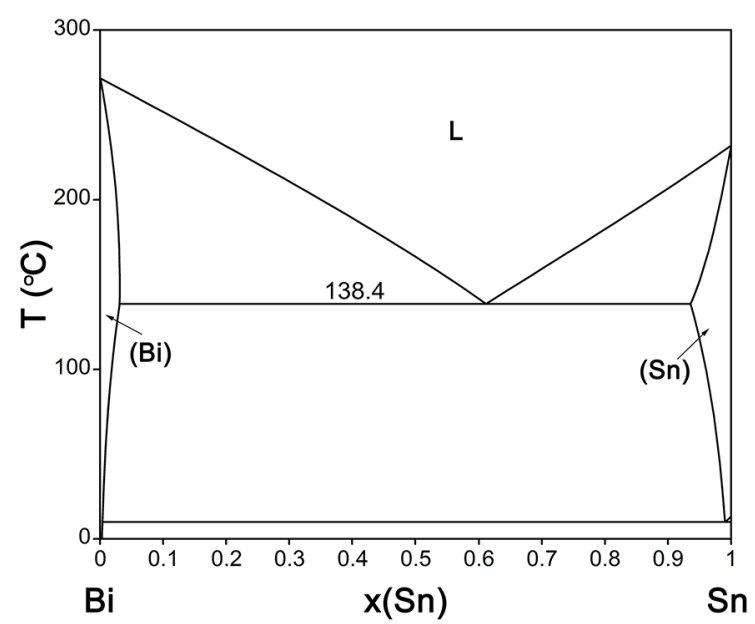

Figure 1. Calculated phase diagram of the Bi-Sn binary system using thermodynamic parameters from the COST 531 database $^{15}$.

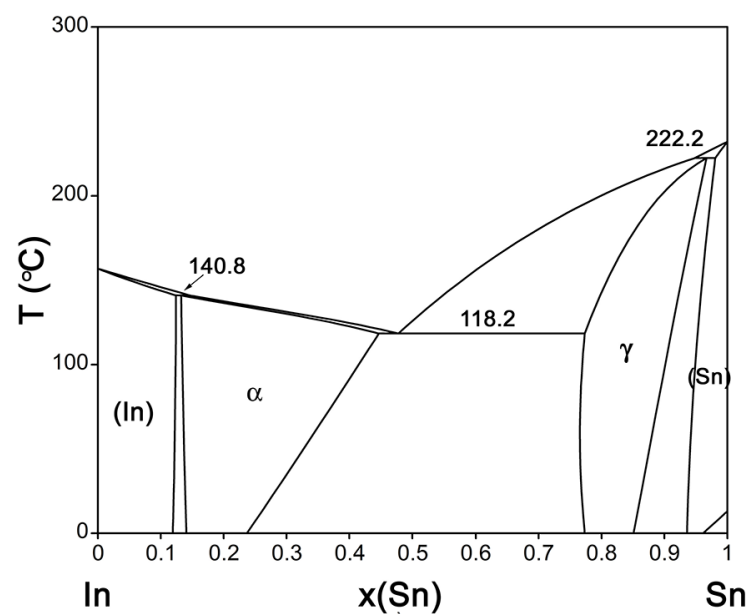

Figure 2. Calculated phase diagram of the In-Sn binary system using thermodynamic parameters from the COST 531 database $^{15}$.

$\left(\mathrm{Tm}=138.4{ }^{\circ} \mathrm{C}\right.$ for $\mathrm{Sn}-\mathrm{Bi}$ solder and $\mathrm{Tm}=118.2^{\circ} \mathrm{C}$ for In-Sn solder) and do not form brittle intermetallics as SnAg-Cu solders ${ }^{20}$.

Figure 3. shows calculated phase diagram of the $\mathrm{Bi}$-In system using optimized thermodynamic parameters from the COST 531 database ${ }^{15}$, which are based on the thermodynamic assessment by Boa and Ansara ${ }^{21}$.

The Bi-In system includes four intermediate compounds: the BiIn, $\mathrm{Bi}_{3} \mathrm{In}_{5}, \mathrm{BiIn}_{2}$, and $\beta$ phases. The crystal structure of the $\beta$ phase is similar to that of the $\beta$ phase in the In-Sn system. Three eutectic reactions appear in the Bi-In system. Pan et al. ${ }^{22}$ analytically and experimentally investigated melting points and latent heats of melting for several Bi-In alloys. Microstructure, eutectic morphology, and latent heats of melting of the Bi-In eutectic alloys have been recently investigated by Manasijević et al. ${ }^{23}$.

The summary of solid phases from the constitutive binary subsystems with their crystallographic data ${ }^{19}$ is shown in Table 1.

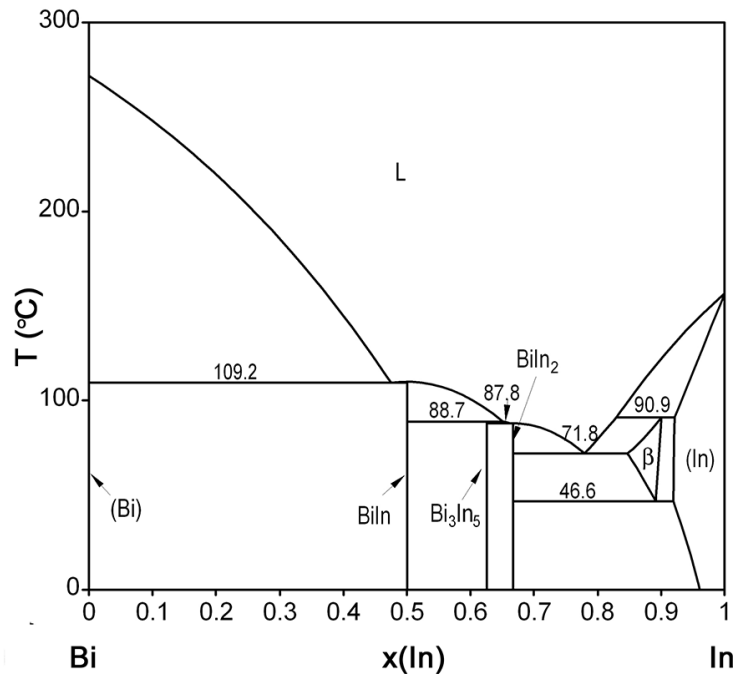

Figure 3. Calculated phase diagram of the Bi-In binary system using thermodynamic parameters from the COST 531 database ${ }^{15}$.

Table 1. Solid phases from the Bi-In, Bi-Sn and In-Sn constitutive binary systems with their crystallographic data ${ }^{24}$

\begin{tabular}{lccc}
\hline $\begin{array}{l}\text { Binary } \\
\text { system }\end{array}$ & Phase & $\begin{array}{c}\text { Pearson } \\
\text { symbol }\end{array}$ & $\begin{array}{c}\text { Strukturbericht } \\
\text { designation }\end{array}$ \\
\hline Bi-In, Bi-Sn & $(\mathrm{Bi})$ & $h R 2$ & $A 7$ \\
Bi-In, In-Sn & $(\mathrm{In})$ & $t I 2$ & $A 6$ \\
Bi-In & $\mathrm{BiIn}$ & $t P 4$ & $B 10$ \\
Bi-In & $\mathrm{Bi}_{3} \mathrm{In}_{5}$ & $t I 32$ & $D 8_{1}$ \\
Bi-In & $\mathrm{BiIn}_{2}$ & $h P 6$ & $B 8_{2}$ \\
Bi-In, In-Sn & $\beta$ & $t I 2$ & $A 6 \bmod$ \\
Bi-Sn, In-Sn & $(\mathrm{Sn})$ & $t I 4$ & $A 5$ \\
In-Sn & $\gamma$ & $h P 1$ & $A f$ \\
\hline
\end{tabular}

Phase diagram of the ternary Bi-In-Sn system was experimentally investigated by Kabassis and Rutter ${ }^{25-27}$. Their proposed phase diagram includes totally six invariant reactions, five eutectic reactions and one peritectic reaction. Later on, Yoon at al. ${ }^{12}$ experimentally re-examined phase relations in the Bi-In-Sn system and thermodynamically assessed ternary phase diagram using the CALPHAD method ${ }^{28,29}$. Their assessed phase diagram significantly differs from the previously proposed phase diagram by Kabassis and Rutter ${ }^{25}$. It includes seven invariant reactions involving the liquid phase, six of them being ternary quasi-peritectic reactions and only one ternary eutectic reaction Liquid $\leftrightarrow \beta+\mathrm{BiIn}+\mathrm{Bi}_{3} \mathrm{In}_{5}$ at $59.5^{\circ} \mathrm{C}$. Alloy composition at the eutectic point is 35.86 wt.\% Bi, 50.10 wt.\% In and 14.04 wt.\% Sn.

Due to the changes to the binary data (Bi-In, Bi-Sn), the Bi-In-Sn system was re-assessed in the scope of the COST 531 Action $^{14}$. Optimized phase diagram includes 7 invariant reactions, which is in agreement with the results of Yoon at al. ${ }^{12}$. However, there is dissimilarity regarding the ternary eutectic composition, eutectic temperature and involved solid phases. Calculated ternary eutectic reaction is Liquid $\leftrightarrow \beta+\mathrm{BiIn}_{2}+\gamma$ at 
$55.3{ }^{\circ} \mathrm{C}$. Calculated alloy composition at the eutectic point is 31.4 wt.\% $\mathrm{Bi}, 51.4$ wt.\% In and 17.2 wt.\% $\mathrm{Sn}$. Based on the experimental data from previous studies and their own experimental results Witusiewicz et al. ${ }^{30}$ presented a new thermodynamic description for the ternary Bi-In-Sn system in the entire composition range. They determined 5 invariant reactions, three ternary quasi-peritectic reactions and two ternary eutectic reactions (Figure 4). Summary of the ternary eutectic reactions from previous thermodynamic descriptions of the ternary Bi-In-Sn system is given in Table 2. The eutectic alloy compositions from Refs..$^{15,30}$ are close to the composition of the commercial low melting Bi-In-Sn alloy known as Field's metal, which consists of 32.5 wt.\% Bi, 51.0 wt.\% In, and 16.5 wt.\% Sn and with approximate melting temperature $62{ }^{\circ} \mathrm{C}$.

Zhou et al. ${ }^{11}$ have recently experimentally investigated microstructure, phase morphology, melting points, and latent heat of melting for several Bi-In-Sn ternary alloys using SEM-EDS, XRD and DSC methods.

It can be concluded that considerable differences in the literature data exist regarding the exact number of ternary eutectic reactions, eutectic alloy compositions, reaction temperatures and involved solid phases. In this study,

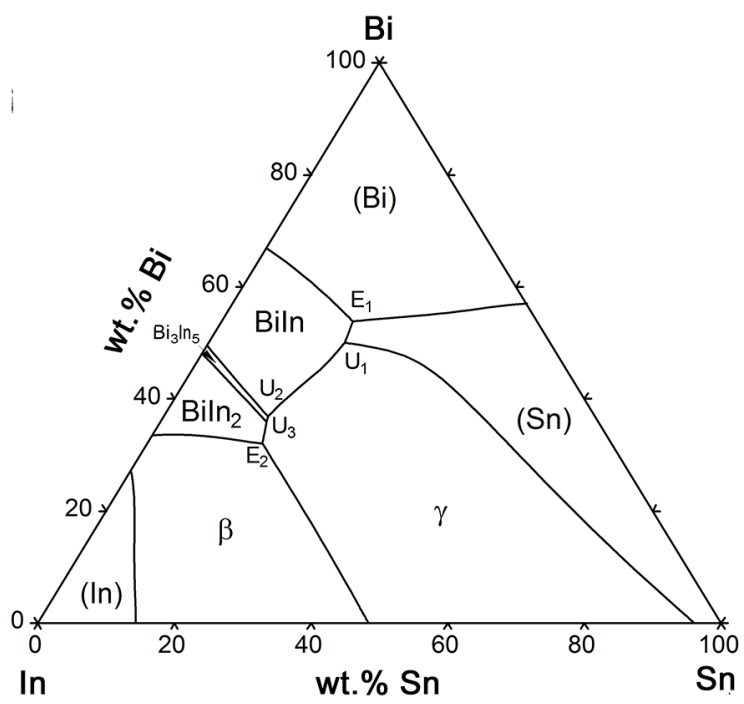

Figure 4. Calculated liquidus projection of the ternary Bi-In-Sn system using the optimized thermodynamic parameters from Witusiewicz et al. ${ }^{30}$. compositions of the investigated Bi-In-Sn eutectic alloys were chosen according to the thermodynamic assessment given by Witusiewicz et al. ${ }^{30}$, as the latest and the most comprehensive study of the ternary Bi-In-Sn system.

\section{Experimental}

Ternary Bi-In-Sn eutectic alloys were prepared by melting of pure elements (Bi 99.999\%, In 99.999\%, Sn 99.99\%, Alfa Aesar). Weighed pieces of $\mathrm{Bi}$, In and $\mathrm{Sn}$ were sealed in quartz tubes under Ar atmosphere, melted in a resistance furnace equipped with a digital controller and kept at $600{ }^{\circ} \mathrm{C}$ for 60 minutes in order to get homogeneous liquid alloys which were cooled in air. One piece of around 0.2 grams from each prepared alloy was cut for DSC analysis.

TESCAN VEGA3 scanning electron microscope with energy dispersive spectroscopy (EDS) (Oxford Instruments $\mathrm{X}$-act) was used for microstructure investigation of the prepared alloys and the measurements were carried out at $20 \mathrm{kV}$ accelerating voltage. Overall compositions and compositions of coexisting phases were determined using EDS area and point analysis. For experimental determination of the samples overall compositions EDS spectra were analyzed at a small magnification (100x) over at least five different locations of the sample. Averaged experimentally determined overall compositions of the investigated alloys were in very good agreement with designed compositions. Designed concentrations of all elements in the investigated alloys were within $68 \%$ confidence interval (mean $\pm 0.1 \mathrm{wt} . \%$ ) so the designed compositions were accepted as correct. All SEM images of the microstructure were taken on the polished surface of the studied alloy in the backscattered electron mode (BSE).

Temperatures and latent heats of melting were determined by simultaneous thermal analyser SDT Q600 (TA Instruments). Samples weighing about $50 \mathrm{mg}$ were investigated by performing 5 heating cycles using the heating rate of $5^{\circ} \mathrm{C} / \mathrm{min}$ in the temperature interval from room temperature up to $150^{\circ} \mathrm{C}$. The reference material was empty alumina crucible. Before DSC measurements temperature and heat calibrations were performed using the pure metal standards ( $\mathrm{Bi}$, In and $\mathrm{Zn}$ ) under the measurement conditions.

Table 2. Summary of ternary eutectic reactions from the previous thermodynamic descriptions of the ternary Bi-In-Sn system.

\begin{tabular}{|c|c|c|c|c|}
\hline \multirow{2}{*}{$\mathbf{T}\left({ }^{\circ} \mathbf{C}\right)$} & \multirow{2}{*}{$\begin{array}{c}\text { Ternary eutectic } \\
\text { reaction }\end{array}$} & \multicolumn{2}{|c|}{ Composition of the liquid (wt\%) } & \multirow{2}{*}{ Reference } \\
\hline & & In & Sn & \\
\hline 59.5 & Liquid $\leftrightarrow \beta+B i I n+\mathrm{Bi}_{3} \operatorname{In}_{5}$ & 50.1 & 14.0 & Yoon at al. ${ }^{12}$ \\
\hline 55.3 & Liquid $\leftrightarrow \beta+$ BiIn $_{2}+\gamma$ & 51.4 & 17.2 & COST 531 database $^{15}$ \\
\hline 76.4 & Liquid $\leftrightarrow(\mathrm{Sn})+(\mathrm{Bi})+$ BiIn & 27.0 & 19.2 & Witusiewicz et al. ${ }^{30}$ \\
\hline 59.2 & Liquid $\leftrightarrow \beta+$ BiIn $_{2}+\gamma$ & 51.2 & 16.8 & Witusiewicz et al. ${ }^{30}$ \\
\hline
\end{tabular}




\section{Results and Discussion}

\subsection{Thermodynamic calculation}

Thermodynamic calculation of phase equilibria using CALPHAD approach ${ }^{28,29}$ can provide valuable information about expected microstructure, phase transformation temperatures and the thermal properties of the investigated material. In this work thermodynamic calculations were performed using thermodynamic dataset from Witusiewicz et al.$^{30}$. Figure 5 and 6 show calculated phase fractions vs. temperature dependences for the investigated 53.8wt.\%Bi-27.0wt.\%In-19.2wt.\%Sn ( $\mathrm{E}_{1}$ alloy) and 32.0wt.\%Bi-51.2wt.\%In-16.8wt.\%Sn ( $\mathrm{E}_{2}$ alloy) eutectic alloys. It can be seen that at eutectic temperatures (76.4 for $\mathrm{E}_{1}$ alloy and $59.2{ }^{\circ} \mathrm{C}$ for $\mathrm{E}_{2}$ alloy) liquid phase isothermally decomposes into three solid phases according to the Liquid $\leftrightarrow(\mathrm{Sn})+(\mathrm{Bi})+$ BiIn and Liquid $\leftrightarrow \beta+\mathrm{BiIn}_{2}+\gamma$ the ternary eutectic reactions. According to the results of thermodynamic calculation, in the case of the $\mathrm{E}_{1}$ alloy, the

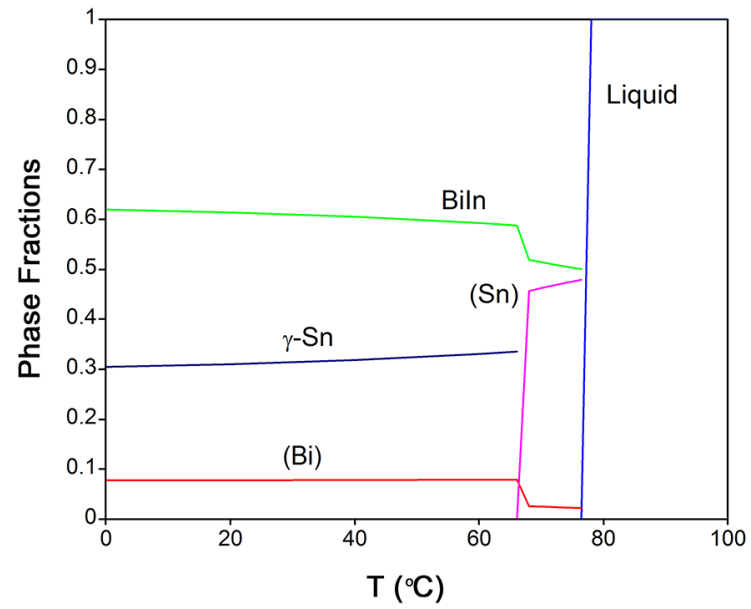

Figure 5. Calculated phase fractions vs. temperature dependence for the investigated $53.8 \% \mathrm{Bi}-27.0 \% \mathrm{In}-19.2 \% \mathrm{Sn}$ alloy using the optimized thermodynamic parameters from Witusiewicz et al. ${ }^{30}$.

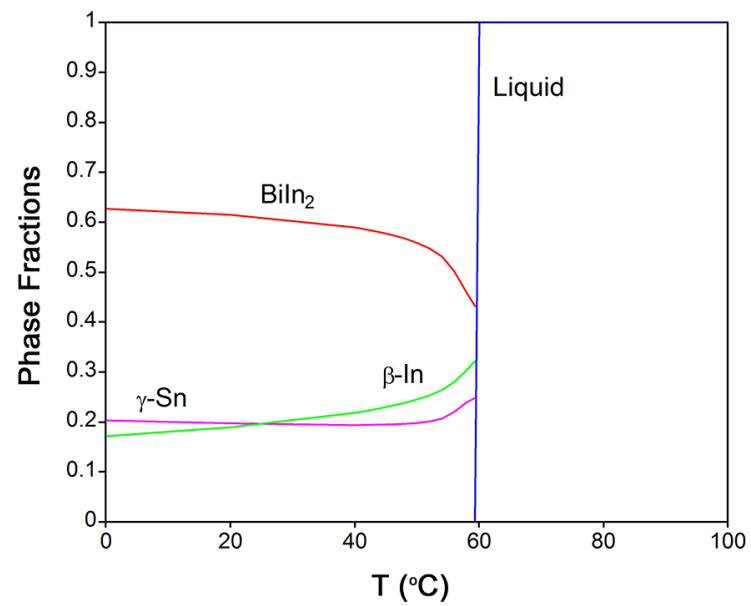

Figure 6. Calculated phase fractions vs. temperature dependence for the investigated $32.0 \% \mathrm{Bi}-51.2 \% \mathrm{In}-16.8 \% \mathrm{Sn}$ alloy using the optimized thermodynamic parameters from Witusiewicz et al. ${ }^{30}$.
BiIn compound has the largest phase fraction and the (Bi) phase the smallest phase fraction (less than 0.1). In the case of the $\mathrm{E}_{2}$ alloy, the BiIn ${ }_{2}$ compound has the largest phase fraction and $\beta$ and $\gamma$ phases have roughly equal phase fractions.

\subsection{Microstructure investigation}

The eutectic alloys from the Bi-In-Sn ternary system with the designed compositions corresponding to the calculated ternary eutectic points $E_{1}$ and $E_{2}$ (Figure 4) were studied using scanning electron microscopy (SEM) combined with energy dispersive X-ray spectroscopy (EDS).

Characteristic SEM micrographs of the investigated eutectic alloys are shown in Figure 7 and Figure 8.

It was determined that microstructure of the ternary $53.8 \% \mathrm{Bi}-27.0 \% \mathrm{In}-19.2 \% \mathrm{Sn}$ eutectic alloy includes three phases: BiIn as a grey phase, $(\mathrm{Sn})$ as a dark phase and $(\mathrm{Bi})$ as a bright phase. Most abundant phase in the microstructure is the grey phase. Based on the results of EDS analysis (Table 3) this phase corresponds to the Biln binary compound. This result is in agreement with the calculated diagram of phase fractions of stable phases as a function of temperature shown in Figure 5. No solubility of $\mathrm{Sn}$ in the BiIn phase was experimentally identified. Sn-rich phase appears as a dark phase in Figs. 5a-b. The experimentally determined content of $\mathrm{Sn}$ in the ( $\mathrm{Sn}$ ) phase (92.9 at.\%) is much higher than calculated (51.0 at.\%). Third detected phase with the smallest phase fraction is (Bi) phase, which is in agreement with the calculated results given in Figure 5. Identified coexisting phases and phase morphology are in good agreement with the results of Zhou et al. ${ }^{11}$ obtained for the $57.5 \% \mathrm{Bi}$ $25.2 \% \operatorname{In}-17.3 \% \mathrm{Sn}$ (wt.\%) alloy.

Three co-existing phases were also detected in the microstructure of the $32.0 \% \mathrm{Bi}-51.2 \% \mathrm{In}-16.8 \% \mathrm{Sn} \mathrm{E}_{1}$ eutectic alloy: BiIn ${ }_{2}$ light phase, $\beta$-In grey phase, $\gamma$-Sn dark phase. The chemical composition of the BiIn 2 phase is close to the calculated composition (Table 3). No solubility of tin in the $\mathrm{BiIn}_{2}$ phase was experimentally determined.

Experimentally determined content of $\mathrm{Bi}(26.8$ at.\%) in the In-rich $\beta$ phase is considerably higher than calculated content of $\mathrm{Bi}$ at eutectic temperature (8.8 at.\%). Third identified phase with the smallest phase fraction is Sn-rich dark $\gamma$ phase. Experimentally determined content of $\mathrm{Sn}$ in the Sn-rich $\gamma$ phase (60.5 at.\%) is considerably larger than corresponding calculated content (43.4 at.\%) (Table 3).

\subsection{Thermal analysis}

DSC heating cycles were used for measurements of eutectic (melting) temperatures and latent heats of melting for the investigated Bi-In-Sn eutectic alloys. The extrapolated temperature of the peak onset was used for determination of eutectic temperature of the sample ${ }^{31}$.

Average values of eutectic temperatures and latent heats together with related standard uncertainties obtained from five conducted DSC heating cycles are presented in Table 4. 

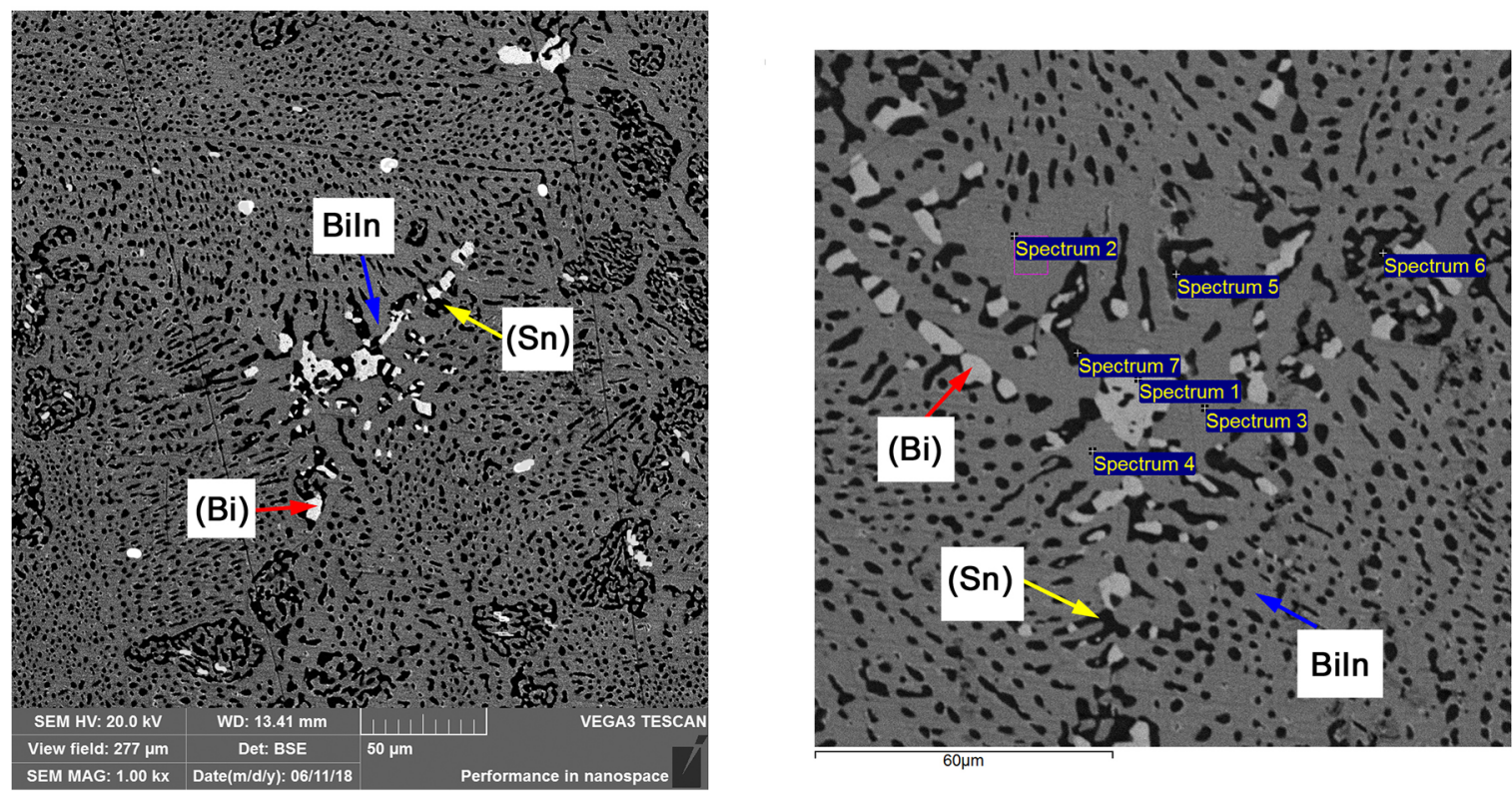

Figure 7. SEM micrographs of the investigated 53.8\%Bi-27.0\%In-19.2\% Sn eutectic alloy: (Bi) light phase, BiIn grey phase, (Sn) dark phase.
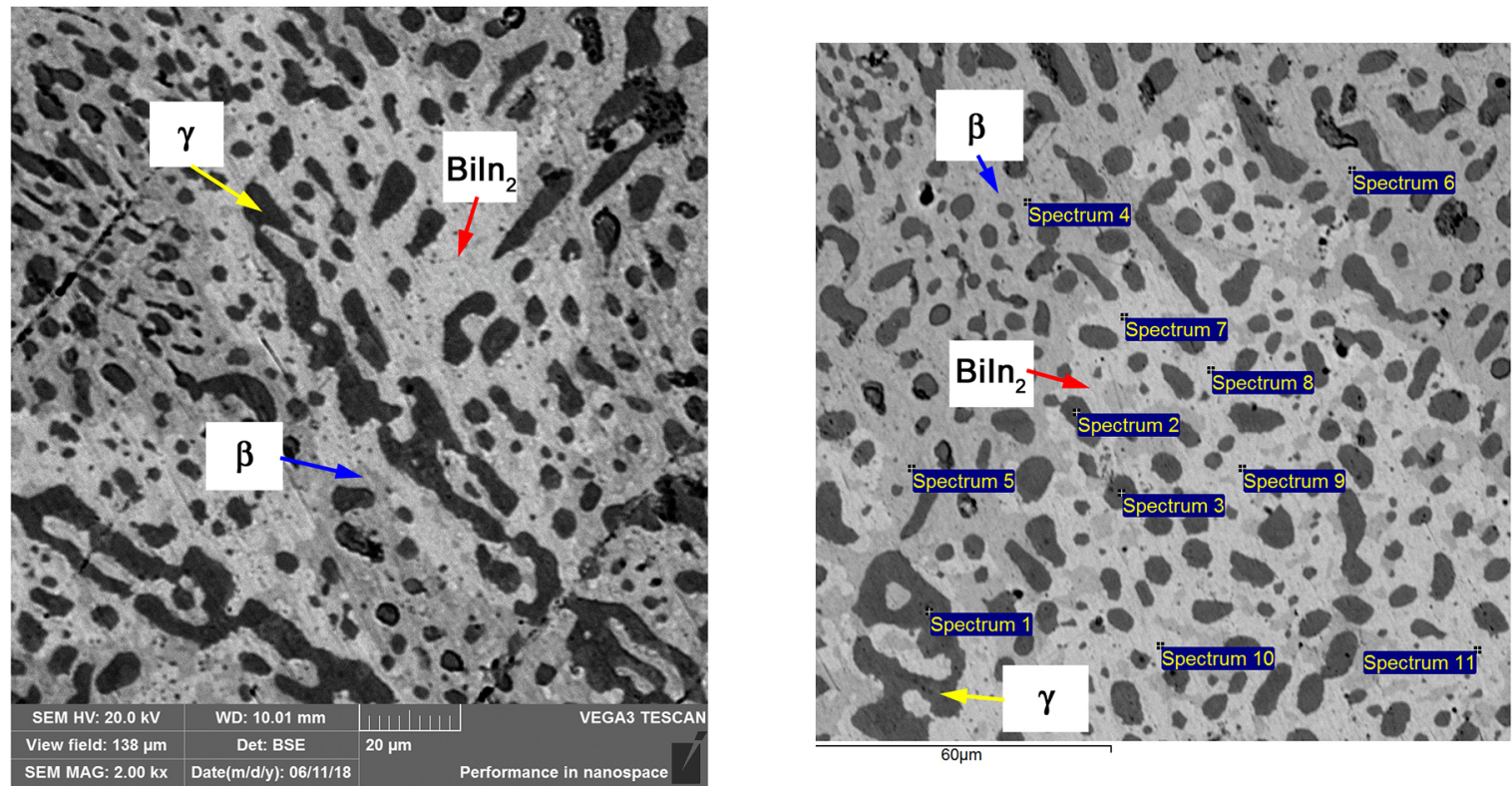

Figure 8. SEM micrographs of the investigated 32.0\%Bi-51.2\%In-16.8\%Sn eutectic alloy: BiIn 2 light phase, $\beta$-In grey phase, $\gamma$-Sn dark phase.

DSC curves from the third heating cycle for the investigated $53.8 \% \mathrm{Bi}-27.0 \% \mathrm{In}-19.2 \% \mathrm{Sn}\left(\mathrm{E}_{1}\right)$ eutectic alloy and $32.0 \% \mathrm{Bi}-$ $51.2 \% \mathrm{In}-16.8 \% \mathrm{Sn}\left(\mathrm{E}_{2}\right)$ eutectic alloy are shown in Figure $9 \mathrm{a}-\mathrm{b}$ as an illustration.

Experimentally determined melting temperature for the $53.8 \% \mathrm{Bi}-27.0 \% \mathrm{In}-19.2 \% \mathrm{Sn}\left(\mathrm{E}_{1}\right)$ eutectic alloy $\left(76.6^{\circ} \mathrm{C}\right)$ is in very good agreement with the calculated value $\left(76.4^{\circ} \mathrm{C}\right)$. Experimentally determined latent heat of melting of the $32.0 \% \mathrm{Bi}-51.2 \% \mathrm{In}-16.8 \% \mathrm{Sn}\left(\mathrm{E}_{2}\right)$ eutectic alloy, $25.4 \mathrm{~J} / \mathrm{g}$, is relatively small, close to the latent heat of melting for pure indium $(28.5 \mathrm{~J} / \mathrm{g})$ and much smaller than latent heat of melting of pure $\mathrm{Bi}(53.3 \mathrm{~J} / \mathrm{g})$ and pure $\mathrm{Sn}(60.5 \mathrm{~J} / \mathrm{g})^{6}$. Yang et al. ${ }^{2}$ have recently investigated melting point and latent heat of melting for the Bi-In-Sn alloy with $31.6 \mathrm{wt} \%$ of $\mathrm{Bi}$, $48.8 \mathrm{wt} \%$ of In and $19.6 \mathrm{wt} \%$ of $\mathrm{Sn}$. Their measured values, obtained using DSC method, are $60.2{ }^{\circ} \mathrm{C}$ for melting point and $27.9^{\circ} \mathrm{C}$ for latent heat. It can be seen that measured temperature from this work obtained in heating regime is to some extent higher than those from Ref. ${ }^{2}$.

Based on the obtained results it can be concluded that investigated Bi-In-Sn alloys have a small latent heats based on the weight, but a large latent heats based on the volume. This is characteristic for many low melting eutectic alloys based on bismuth and indium ${ }^{6,11}$. Due to the relatively large 
Table 3. Experimentally determined compositions of co-existing phases by EDS analysis and related calculated equilibrium compositions of solid phases at eutectic temperatures for the investigated $\mathrm{Bi}-\mathrm{In}-\mathrm{Sn}$ eutectic alloys

\begin{tabular}{|c|c|c|c|c|c|c|c|c|}
\hline \multirow{3}{*}{$\begin{array}{l}\text { Overall exp. } \\
\text { composition (wt.\%) }\end{array}$} & \multicolumn{2}{|c|}{ Phases } & \multicolumn{6}{|c|}{ Compositions of phases (at.\%) } \\
\hline & \multirow{2}{*}{ Calc. } & \multirow{2}{*}{ Exp. } & \multicolumn{2}{|c|}{$\mathbf{B i}$} & \multicolumn{2}{|c|}{ In } & \multicolumn{2}{|c|}{ Sn } \\
\hline & & & Calc. & Exp. & Calc. & Exp. & Calc. & Exp. \\
\hline \multirow{3}{*}{$\begin{array}{l}53.8 \% \text { Bi-27.0\%In- } \\
19.2 \% \text { Sn E E eutectic } \\
\text { alloy }\end{array}$} & BiIn & BiIn (Grey phase) & 49.4 & 51.6 & 50.0 & 48.4 & 0.6 & 0.0 \\
\hline & $(\mathrm{Sn})$ & (Sn) (Dark phase) & 26.1 & 7.1 & 22.9 & 0.0 & 51.0 & 92.9 \\
\hline & (Bi) & (Bi) (Light phase) & 100.0 & 100.0 & 0.0 & 0.0 & 0.0 & 0.0 \\
\hline \multirow{3}{*}{$\begin{array}{l}32.0 \% \mathrm{Bi}-51.2 \% \text { In- } \\
16.8 \% \mathrm{Sn} \quad \mathrm{E}_{2} \text { eutectic } \\
\text { alloy }\end{array}$} & $\mathrm{BiIn}_{2}$ & BiIn $_{2}$ (Light phase) & 32.0 & 36.8 & 66.7 & 63.2 & 1.3 & 0.0 \\
\hline & $\beta$-In & $\beta$-In (Grey phase) & 8.8 & 26.8 & 66.8 & 61.3 & 24.5 & 11.9 \\
\hline & $\gamma-\mathrm{Sn}$ & $\gamma$-Sn (Dark phase) & 16.2 & 8.2 & 40.4 & 31.3 & 43.4 & 60.5 \\
\hline
\end{tabular}

Table 4. DSC results for the investigated ternary Bi-In-Sn eutectic alloys from this study

\begin{tabular}{lcccc}
\hline & \multicolumn{2}{c}{ DSC results } & \multicolumn{2}{c}{ Calculation } \\
\cline { 2 - 5 } & $\begin{array}{c}\text { Eutectic } \\
\text { temperature }\left({ }^{\circ} \mathbf{C}\right)\end{array}$ & $\begin{array}{c}\text { Latent heat of } \\
\text { melting(J/g) }\end{array}$ & $\begin{array}{c}\text { Eutectic } \\
\text { temperature }\left({ }^{\circ} \mathbf{C}\right)\end{array}$ & $\begin{array}{c}\text { Latent heat of } \\
\text { melting }(\mathbf{J} / \mathbf{g})\end{array}$ \\
\hline $53.8 \% \mathrm{Bi}-27.0 \% \mathrm{In}-19.2 \% \mathrm{Sn}$ & $76.6 \pm 0.2$ & $32.6 \pm 0.1$ & 76.4 & $34.5 \mathrm{~J} / \mathrm{g}$ \\
$32.0 \% \mathrm{Bi}-51.2 \% \mathrm{In}-16.8 \% \mathrm{Sn}$ & $60.8 \pm 0.1$ & $25.4 \pm 0.1$ & 59.2 & $26.7 \mathrm{~J} / \mathrm{g}$ \\
\hline
\end{tabular}
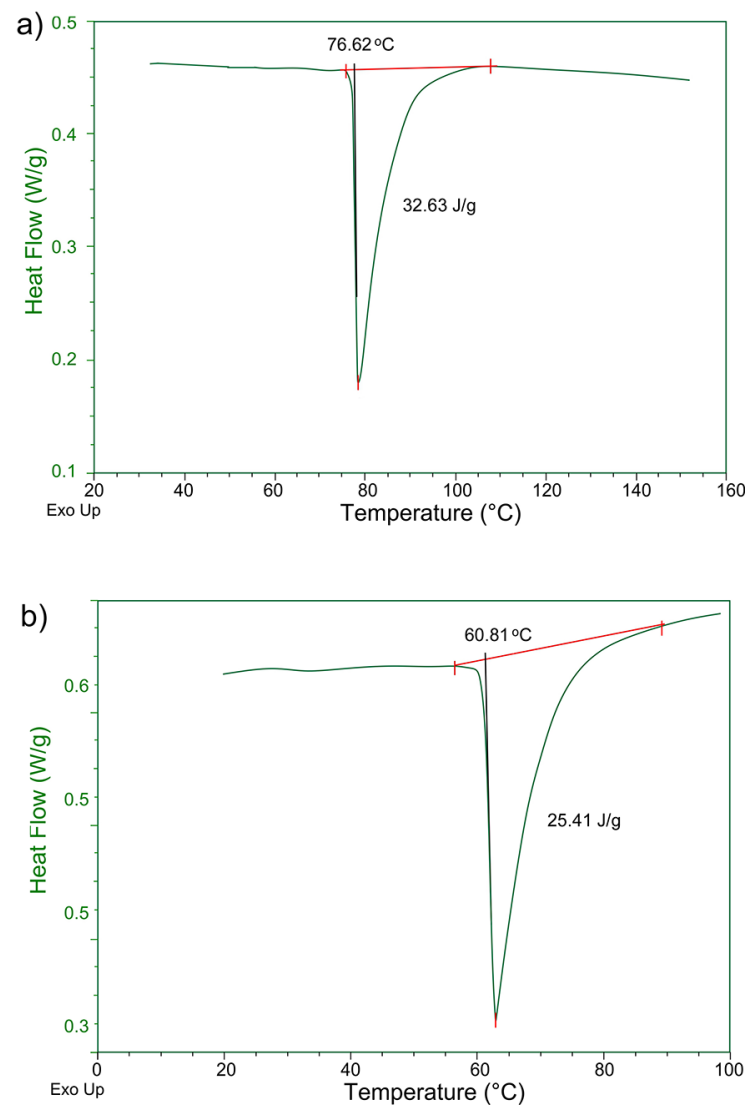

Figure 9. DSC heating curve: (a) 53.8\%Bi-27.0\% In-19.2\% $\mathrm{Sn}\left(\mathrm{E}_{1}\right)$ eutectic alloy; (b) $32.0 \% \mathrm{Bi}-51.2 \% \mathrm{In}-16.8 \% \mathrm{Sn}\left(\mathrm{E}_{2}\right)$ eutectic alloy.

latent heat per unit volume and large density, these alloys are potentially suitable for applications with the restricted heat dissipation space, within which the metal PCM can absorb large amount of heat efficiently ${ }^{6}$.

\section{Conclusion}

Two low melting Bi-In-Sn eutectic alloys with potential for usage as metallic PCM was studied in this work. In the first part of the work CALPHAD methodology and the optimized thermodynamic parameters from the latest thermodynamic optimization of the ternary Bi-In-Sn system was used to calculate liquidus projection of the ternary Bi-In-Sn system and to precisely determine compositions of the ternary eutectic alloys. Next, two ternary Bi-In-Sn alloys with target eutectic compositions were prepared by melting of pure metals. Microstructure and chemical compositions of the prepared alloys were investigated using SEM-EDS technique. Overall compositions and compositions of co-existing phases were determined using EDS analysis and compared with the results of thermodynamic calculations. It was determined that microstructure of the $53.8 \% \mathrm{Bi}-27.0 \% \mathrm{In}-19.2 \% \mathrm{Sn}$ alloy includes BiIn intermetallic compound, ( $\mathrm{Sn})$ and $(\mathrm{Bi})$ phases. Microstructure of the $32.0 \% \mathrm{Bi}-51.2 \% \mathrm{In}-16.8 \% \mathrm{Sn}$ alloy includes BiIn $_{2}$ phase, In-rich $\beta$ phase and Sn-rich $\gamma$ phase, which is in agreement with thermodynamic calculations. Experimentally determined chemical compositions of phases were compared with equilibrium phase compositions at eutectic temperature. The results show significant differences between calculated and experimentally determined phase compositions in the case of (Sn), $\beta$ and $\gamma$ phases.

Melting temperatures and latent heat of eutectic melting were investigated using DSC technique. Five heating cycles with the heating rate of $5^{\circ} \mathrm{C} / \mathrm{min}$ in the temperature interval from room temperature up to $150{ }^{\circ} \mathrm{C}$ were performed for each alloy. Experimentally obtained results were in good agreement with calculated values. For the $53.8 \% \mathrm{Bi}-27.0 \% \mathrm{In}-$ $19.2 \% \mathrm{Sn}$ alloy, calculated melting temperature was $76.4^{\circ} \mathrm{C}$ and average eutectic temperature of five heating runs was 
$76.6{ }^{\circ} \mathrm{C}$ Calculated latent enthalpy of melting was 34.5 $\mathrm{J} / \mathrm{g}$ and average latent heat of melting obtained from DSC heating runs was $32.6 \mathrm{~J} / \mathrm{g}$.

For the $32.0 \% \mathrm{Bi}-51.2 \% \mathrm{In}-16.8 \% \mathrm{Sn}$ alloy, the average eutectic temperature from five heating runs was $60.8^{\circ} \mathrm{C}$ which is to some extent higher than related calculated temperature $59.2^{\circ} \mathrm{C}$. Calculated latent enthalpy of melting was $26.7 \mathrm{~J} / \mathrm{g}$ and average latent heat of melting obtained from DSC heating runs was $25.4 \mathrm{~J} / \mathrm{g}$.

The results of experimental and analytical characterization of low melting Bi-In-Sn eutectic alloys represent contribution to the better understanding of microstructure and thermal properties of these alloys as candidate metallic PCMs.

\section{Acknowledgement}

This work has been supported by the Ministry of Education, Science and Technological Development of the Republic of Serbia, Project No. ON172037. The authors are grateful to V.T. Witusiewicz for kindly providing TDB file for thermodynamic calculations.

\section{References}

1. Yang XH, Tan SC, Liu J. Numerical investigation of the phase change process of low melting point metal. International Journal of Heat and Mass Transfer. 2016;100:899-907. DOI: https://doi.org/10.1016/j.ijheatmasstransfer.2016.04.109

2. Yang XH, Tan SC, Ding YJ, Wang L, Liu J, Zhou YX. Experimental and numerical investigation of low melting point metal based PCM heat sink with internal fins. International Communications in Heat and Mass Transfer. 2017;87:118-124. DOI: https://doi.org/10.1016/j.icheatmasstransfer.2017.07.001

3. Fleischer AS. Thermal Energy Storage Using Phase Change Materials: Fundamentals and Applications. Cham: Springer; 2015.

4. Tan FL, Tso CP. Cooling of mobile electronic devices using phase change materials. Applied Thermal Engineering. 2004;24(2-3):159-169. DOI: https://doi.org/10.1016/j. applthermaleng.2003.09.005

5. Kandasamy R, Wang XQ, Mujumdar AS. Transient cooling of electronics using phase change material (PCM)-based heat sinks. Applied Thermal Engineering. 2008;28(8-9):1047-1057. DOI: https://doi.org/10.1016/j.applthermaleng.2007.06.010

6. Ge H, Li H, Mei S, Liu J. Low melting point liquid metal as a new class of phase change material: An emerging frontier in energy area. Renewable and Sustainable Energy Reviews. 2013; 21:331-346. DOI: http://dx.doi.org/10.1016/j.rser.2013.01.008

7. Zhang H, Xu Q, Zhao Z, Zhang J, Sun Y, Sun L, et al. Preparation and thermal performance of gypsum boards incorporated with microencapsulated phase change materials for thermal regulation. Solar Energy Materials and Solar Cells. 2012;102:93-102. DOI: http://dx.doi.org/10.1016/j. solmat.2012.03.020
8. Adinberg R, Zvegilsky D, Epstein M. Heat transfer efficient thermal energy storage for steam generation. Energy Conversion and Management. 2010;51(1):9-15. DOI: http://dx.doi. org/10.1016/j.enconman.2009.08.006

9. Swanson TD, Birur GC. NASA thermal control technologies for robotic spacecraft. Applied Thermal Engineering. 2003;23(9):10551065. DOI: https://doi.org/10.1016/S1359-4311(03)00036-X

10. Sharma A, Tyagi VV, Chen CR, Buddhi D. Review on thermal energy storage with phase change materials and applications. Renewable and Sustainable Energy Reviews. 2009;13(2):318345. DOI: https://doi.org/10.1016/j.rser.2007.10.005

11. Zhou K, Tang Z, Lu Y, Wang T, Wang H, Li T. Composition, Microstructure, Phase Constitution and Fundamental Physicochemical Properties of Low-Melting-Point MultiComponent Eutectic Alloys. Journal of Materials Science \& Technology. 2017;33(2):131-154. DOI: http://dx.doi.org/10.1016/j. jmst.2016.08.022

12. Yoon SW, Rho BS, Lee HM, Kim CU, Lee BJ. Investigation of the phase equilibria in the Sn-Bi-In alloy system. Metallurgical and Materials Transactions A. 1999:30(6):1503-1515. DOI: https://doi.org/10.1007/s11661-999-0087-8

13. Vizdal J, Braga MH, Kroupa A, Richter KW, Soares D, Malheiros $\mathrm{LF}$, et al. Thermodynamic assessment of the Bi-Sn-Zn System. Calphad.2007;31(4):438-448. DOI: https://doi.org/10.1016/j. calphad.2007.05.002

14. Kroupa A, Dinsdale AT, Watson A, Vrestal J, Zemanova A. Cost531 Project - Study of the Advanced Materials for Lead Free Soldering. Journal of Mining and Metallurgy B. 2007;43(2):113123. DOI: http://dx.doi.org/10.2298/JMMB0702113K

15. Kroupa A, Dinsdale AT, Watson A, Vrestal J, Vízdal J, Zemanova A. The development of the COST 531 lead-free solders thermodynamic database. JOM. 2007;59(7):20-25.

16. Ansara I, Fries S, Lukas HL. Thermodynamic assessment of the In-Sn binary system. Unpublished work. 1999.

17. Moelans N, Hari Kumar KC, Wollants P. Thermodynamic optimization of the lead-free solder system Bi-In-Sn-Zn. Journal of Alloys and Compounds. 2003;360(1-2):98-106. DOI: https:// doi.org/10.1016/S0925-8388(03)00325-6

18. Silva BL, Reinhart G, Nguyen-Thi H, Mangelinck-Noël N, Garcia A, Spinelli JE. Microstructural development and mechanical properties of a near-eutectic directionally solidified Sn-Bi solder alloy. Materials Characterization. 2015;107:4353. DOI: https://doi.org/10.1016/j.matchar.2015.06.026

19. El-Daly AA, Ibrahiem AA. Influence of rotating magnetic field on solidification microstructure and tensile properties of $\mathrm{Sn}-\mathrm{Bi}$ lead-free solders. Microelectronics Reliability. 2018;81:352361. DOI: https://doi.org/10.1016/j.microrel.2017.10.035

20. Chang SH, Wu SK. Low-frequency damping properties of eutectic Sn-Bi and In-Sn solders. Scripta Materialia. 2011;64(8):757760. DOI: https://doi.org/10.1016/j.scriptamat.2010.12.035

21. Boa D, Ansara I. Thermodynamic assessment of the ternary system Bi-In-Pb. Thermochimica Acta. 1998;314(1-2):79-86. DOI: https://doi.org/10.1016/S0040-6031(98)00237-8 
22. Pan A, Wang J, Zhang X. Prediction of Melting Temperature and Latent Heat for Low-melting Metal PCMs. Rare Metal Materials and Engineering. 2016;45(4):874-880. DOI: https://doi.org/10.1016/ S1875-5372(16)30091-1

23. Manasijevic I, Balanovic L, Grguric TH, Minic D, Gorgievski M. Study of microstructure and thermal properties of the low-melting Bi-In eutectic alloys. Journal of Thermal Analysis and Calorimetry. 2018. DOI: https://doi.org/10.1007/s10973-018-7679-8

24. Dinsdale A, Watson A, Kroupa A, Vrestal J, Zemanova A, Vizdal J. COST 531 -Atlas of Phase Diagrams for Lead Free Soldering. Brussels: COST; 2008.

25. Kabassis H, Rutter JW, Winegard WC. Microstructure of one of the ternary eutectic alloys in the Bi-In-Sn system. Metallurgical and Materials Transactions A. 1984;15(8):1515-1517. DOI: https:// doi.org/10.1007/BF02657790

26. Kabassis H, Rutter JW, Winegard WC. Phase relationships in Bi-In-Sn alloy system. Materials Science and Technology. 1986;2(10):985988. DOI: https://doi.org/10.1179/mst.1986.2.10.985
27. Ruggiero MA, Rutter JW. Origin of microstructure in $350 \mathrm{~K}$ eutectic of Bi-In-Sn ternary system. Materials Science and Technology. 1995;11(2):136-142. DOI: https://doi.org/10.1179/ mst.1995.11.2.136

28. Saunders N, Miodownik AP, eds. CALPHAD (Calculation of Phase Diagrams): A Comprehensive Guide. Volume 1. London: Pergamon; 1998.

29. Lukas HL, Fries SG, Sundman B. Computational Thermodynamics: The Calphad Method. New York: Cambridge University Press; 2007.

30. Witusiewicz VT, Hecht U, Böttger B, Rex S. Thermodynamic re-optimisation of the Bi-In-Sn system based on new experimental data. Journal of Alloys and Compounds. 2007;428(1-2):115124. DOI: https://doi.org/10.1016/j.jallcom.2006.03.050

31. Boettinger WJ, Kattner UR, Moon KW, Perepezko JH. DTA and Heat-flux DSC Measurements of Alloy Melting and Freezing. In: Zhao JC, ed. Methods for Phase Diagram Determination. Amsterdam: Elsevier Science; 2007. p. 151-221. 